\title{
Neglected intrauterine bilateral congenital knee dislocation
}

\author{
Sevgi Çıraklı, MD (D), Alper Çıraklı, MD (1) \\ ${ }^{1}$ Department of Child Health and Diseases, Division of Pediatric Neurology, Ordu University, Faculty of Medicine, Ordu, Turkey \\ ${ }^{2}$ Department of Orthopedics and Traumatology, Ordu University, Faculty of Medicine, Ordu, Turkey
}

Congenital knee dislocation-subluxation is a rare deformity ${ }^{[1]}$ It was first described by Chanssier in 1812 and later by Chatelain in 1822. ${ }^{[2]}$ Its incidence is 1 in every 1,000 births. ${ }^{[2,3]}$ Its etiology is not certain, and there are frequently accompanying other musculoskeletal abnormalities. ${ }^{[2-5]}$ Conservative treatment methods, which usually consist of early manipulation, have a high chance of success. ${ }^{[4]}$ Surgical treatment is indicated in later stages in neglected or unresponsive cases to manipulation in the early period. ${ }^{[6]}$

In the literature, the first diagnosis was made in the prenatal period as evidenced by a radiograph taken after local trauma in $1986 .^{[2]}$ However, it was first diagnosed with ultrasonography in the prenatal period in 2003. ${ }^{[7]}$ Despite hundreds of cases reported in the literature, antenatal descriptions are very rare. ${ }^{[8]}$ Unlike the case reports in the literature, in this article, we present a rare case of bilateral congenital knee dislocation which was diagnosed after birth.

Received: November 13, 2020

Accepted: January 01, 2021

Published online: June 11, 2021

Correspondence: Alper Çıraklı, MD. Ordu Üniversitesi Tıp

Fakültesi Ortopedi ve Travmatoloji Anabilim Dalı, 52200 Altınoru, Ordu, Türkiye.

E-mail: alperomu@gmail.com

Doi: $10.52312 /$ jdrs.2021.79966

Citation: Cıraklı S, Çıraklı A. Neglected intrauterine bilateral congenital knee dislocation. Jt Dis Relat Surg 2021;32(2):542-545.

(92021 All right reserved by the Turkish Joint Diseases Foundation

This is an open access article under the terms of the Creative Commons Attribution-NonCommercial License, which permits use, distribution and reproduction in any medium, provided the original work is properly cited and is not used for commercial purposes (http://creativecommons.org/licenses/by-nc/4.0/).

\section{ABSTRACT}

Bilateral congenital knee dislocation is a rare deformity which may present with other musculoskeletal abnormalities. In the early period, conservative treatment options have a high chance of success. However, in later stages, surgical treatment is indicated in neglected or unresponsive cases to manipulation in the early period. Herein, we present a rare case of bilateral congenital knee dislocation which was diagnosed after birth. Retrospective examination revealed that it occurred in the antenatal period and neglected.

Keywords: Bilateral, congenital, dislocation, knee, neglected, subluxation.

Retrospective examination revealed that it occurred in the antenatal period and neglected.

\section{CASE REPORT}

Emergency examination was requested for a female, term newborn ( 38 weeks) due to deformity and circulatory disorders in both lower extremities. The patient was evaluated in the delivery room. She was the first child of the parents with breech arrival (up to 30 weeks breech), with a birth weight of $3,475 \mathrm{~g}$ and a height of $50 \mathrm{~cm}$. Physical examination revealed both lower extremity flaccidity, approximately 90 degrees of hyperextension in both knees, and cyanotic appearance in both lower extremities (Figure 1). Both knees were urgently reduced with gentle traction-flexion and circulation returned to normal (Figure 2). Pediatric neurology examination was requested due to flask clinic, but no neurological pathology was considered. Other joint movements of the patient were normal. The patient was followed with ultrasonography during pregnancy, but no information was provided to family about the deformity. The relationship of the baby with the foot and head was suggestive of 

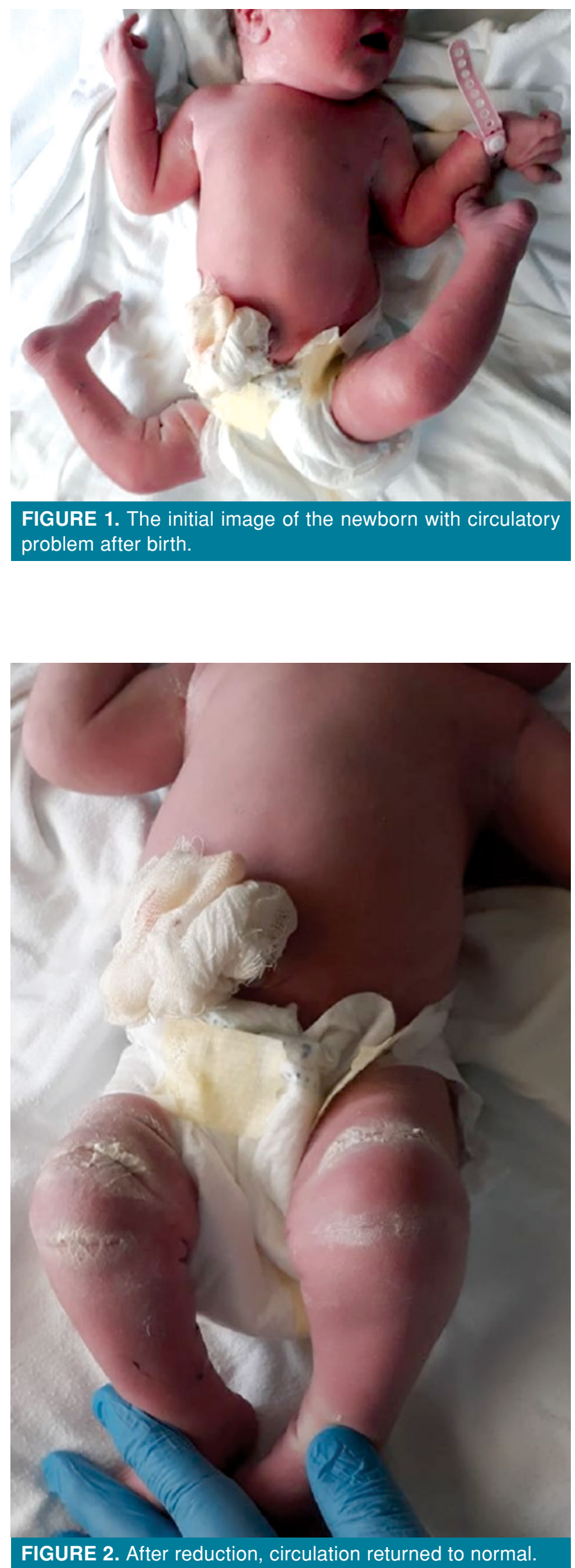

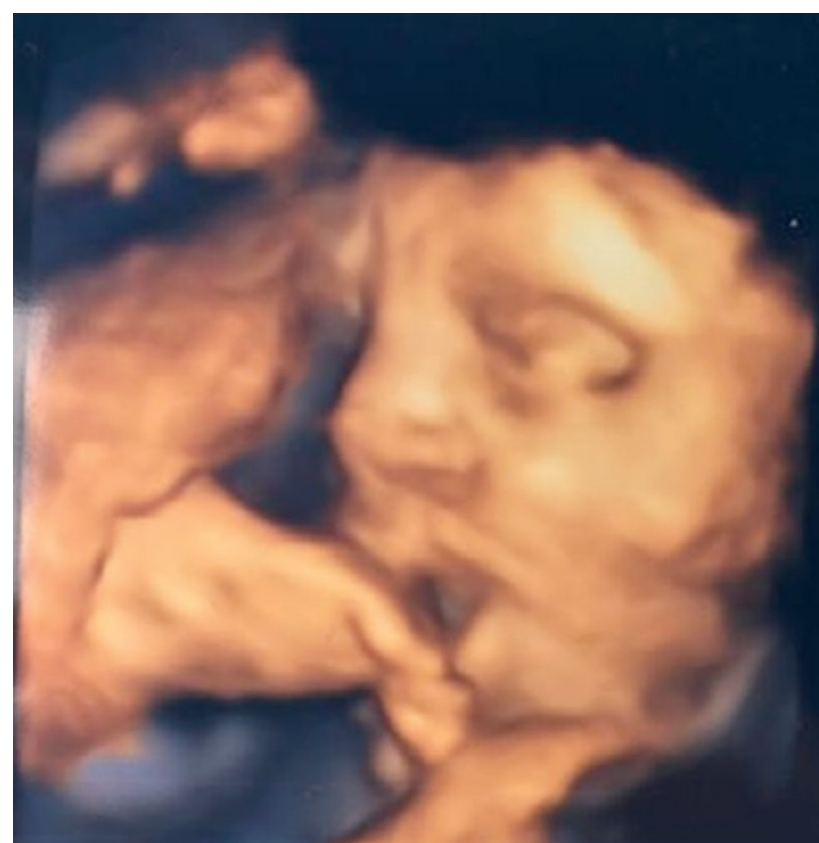

FIGURE 3. Ultrasonography image at 30 weeks of pregnancy showing the relationship of the baby with the foot and head suggestive of the pathology.

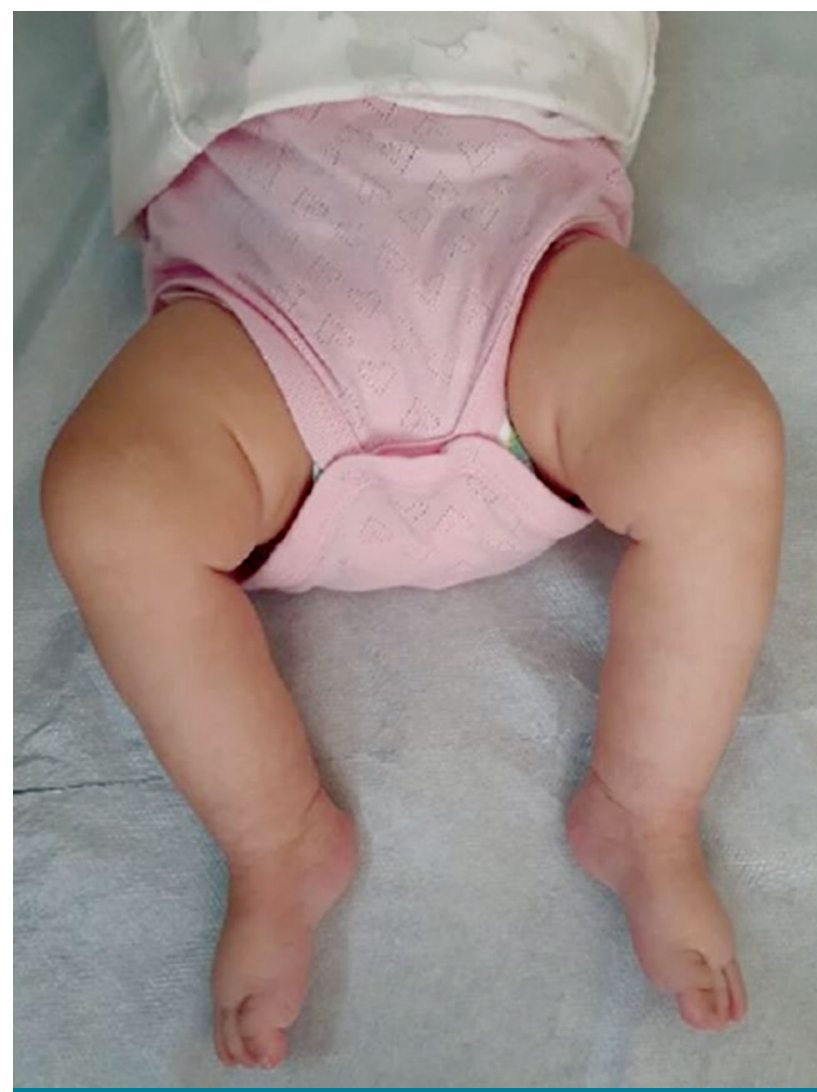

FIGURE 4. Post-treatment image at five months showing recovery. 
congenital knee dislocation on ultrasonography at 30 weeks (Figure 3).

In the treatment, she was followed with a pavlic bandage instead of cast due to circulatory problems. On hip ultrasonography performed in the first month, growth retardation was observed in the left hip. Currently, the treatment of the patient, who was already treated with a pavlic bandage, continued accordingly. The patient, whose bilateral knee joint range of motion was fully restored and no complications developed at five months, continues her life in a healthy way (Figure 4).

A written informed consent was obtained from the parents of the patient for publication of this case.

\section{DISCUSSION}

Bilateral congenital knee dislocation-subluxation is uncommon with an incidence of 1 in 1,000 births and 1 in 100 of developmental hip dysplasia. ${ }^{[1,2,10]}$ It is two-fold more frequent in girls than boys, and there is no difference between the right and left knee and one-third of the cases are bilateral. ${ }^{[1]}$

Although its exact etiology is still unclear, three theories have been proposed as mechanical defect, primary embryological defect, and primary mesenchymal defect. ${ }^{[11]}$ Oligohydramnios can affect the baby's position. ${ }^{[12]}$ Although breech delivery is frequently seen in these patients, it cannot be considered to be the single cause of the disease. ${ }^{[1]}$ Although no etiological factor was found, our case was in the breech presentation position for up to 30 weeks. Different neuromuscular pathologies and syndromes (Larsen, meningomyelocele, or arthrogryposis) have been suggested among the other rare etiological factors. ${ }^{[13]}$ Since the lower extremities were in the flaccid position in our case, a pediatric neurology examination was requested and no pathology was found. There is no sufficient evidence that it is inherited, and most of the cases are sporadic. It may have a polygenic hereditary aspect due to the association with additional anomalies and syndromes. ${ }^{[2,3]}$ In this respect, our case was the first child of the family and had no familial pathology.

Diagnosis is usually made on inspection at first sight; as such, there are varying degrees of hyperextension posture in the knee. In 1946, Leveuf and Pais ${ }^{[14]}$ classified deformity into three groups as hyperextension, subluxation, and dislocation. In 2011, Abdelaziz and Samir ${ }^{[13]}$ made a classification based on range of motion, independent of joint relationship. Direct radiography is widely used to understand the severity of the deformity with the triple-classification system. ${ }^{[2,8,15]}$ Computed tomography and magnetic resonance imaging are rarely used and the condition can be diagnosed prenatally by ultrasonography. ${ }^{[1]}$ In this case, the relationship of the baby with the foot and head was suggestive of congenital knee dislocation at 30 weeks on ultrasonography. In the literature, there is a case diagnosed prenatally with a radiography taken due to trauma. ${ }^{[11]}$ In our case, the diagnosis was made by inspection and, due to the circulatory problems, manipulation and reduction were applied immediately, without any delay. Therefore, direct radiography was taken after the reduction.

Nearly 82 to $88 \%$ of cases with congenital knee dislocation-subluxation have musculoskeletal system abnormalities, particularly lower extremity abnormalities, congenital hip dislocation, and pes equinovarus. ${ }^{[2]}$ Physical examination and hip ultrasonography are important imaging tools in detection of these deformities. As Ooshi et al. ${ }^{[16]}$ describes, additional deformities cannot be successfully treated without a certain knee flexion. In our case, there was developmental failure in the left hip detected by ultrasonography at the first month.

Genu recurvatum deformity is present in the differential diagnosis. Normal healthy babies have a flexion deformity of 20 degrees in the knees. Hyperextension of up to 20 degrees in the knees is considered normal in breech deliveries and in familial ligamentous hyperlaxity. Genu recurvatum does not require any treatment. As the child grows, ligamentous structures develop and the knee becomes more stable. ${ }^{[2,11]}$

The treatment depends on the degree of deformity, the time of initiation of treatment, and whether there are accompanying pathologies. Conservative treatment should be started, as soon as the pathology is recognized. Manipulation, anesthesia with or without serial casting, pavlic bandage, orthosis, and exercises are the main conservative treatment methods. ${ }^{[8,17]}$ The major complication of manipulation and casting is the manipulation fracture and epiphyseal slippage. ${ }^{[1]}$ No pathological condition was confirmed by direct radiography following the manipulation in our case. In a case series of 17 patients, Ko et al. ${ }^{[18]}$ reported that, if there was no concomitant pathology and treatment was started immediately, the chance of success was high. The use of aluminum splint, rather than casting, and flexion exercises are also beneficial. ${ }^{[2]}$ Since our case had a circulatory problem, the treatment was started with a pavlic bandage. In her follow-up, growth retardation was 
detected in the left hip and the pavlic bandage period was prolonged.

In the light of the literature data, conservative methods are preferred in type 1 and type 2 deformities, while surgical methods are indicated in type 3 deformities. ${ }^{[8]}$ Surgical treatment comes into prominence in patients with advanced stages of more than six months in which conservative treatment is insufficient or unsuccessful. Many surgical techniques have been reported in the surgical treatment depending on the age of the patient and the degree of deformity. These include loosening the quadriceps, iliotibial band, adductor and collaterals, and anterior cruciate ligament. ${ }^{[2]}$ In the literature, patients who underwent surgical treatment had additional anomalies, were unresponsive to treatment, and had support tendon pathologies in and around the knee, particularly with the absence of anterior cruciate ligament and hypoplasia. ${ }^{[17,18]}$

Although there are many perinatal diagnoses in the literature, the fact that our case was a neglected intrauterine deformity and the pathology was bilateral with an accompanying circulatory disorder makes our case the first report in the literature.

In conclusion, congenital knee dislocationsubluxation is a rare deformity which can be diagnosed easily. However, accompanying pathologies should be evaluated in these cases. While successful results can be achieved with early conservative treatment, as soon as the diagnosis is made, it is a disease that requires difficult and extensive surgical treatment modalities in neglected cases who do not respond to conservative treatment.

\section{Declaration of conflicting interests}

The authors declared no conflicts of interest with respect to the authorship and/or publication of this article.

Funding

The authors received no financial support for the research and/or authorship of this article.

\section{REFERENCES}

1. BK AR, Singh KA, Shah H. Surgical management of the congenital dislocation of the knee and hip in children presented after six months of age. Int Orthop 2020;44:2635-44.
2. Morales-Roselló J, Loscalzo G, Hueso-Villanueva M, Buongiorno S, Jakaitė V, Perales-Marín A. Congenital knee dislocation, case report and review of the literature. J Matern Fetal Neonatal Med 2020:1-3.

3. Ochoa Del Portillo G, Montanez LFD, Salamanca L. LLuxacion congenita de rodilla bilateral. Reporte de caso. Rev Colomb Ortop Traumatol 2018;32:66-90.

4. Mehrafshan M, Wicart P, Ramanoudjame M, Seringe R, Glorion C, Rampal V. Congenital dislocation of the knee at birth - Part I: Clinical signs and classification. Orthop Traumatol Surg Res 2016;102:631-3.

5. Youssef AO. Limited open quadriceps release for treatment of congenital dislocation of the knee. J Pediatr Orthop 2017;37:192-8.

6. Turan S, Özalp M, Öken F. Surgical treatment of congenital knee subluxation deformity. Eklem Hastalik Cerrahisi 2000;11:124-30.

7. Gorincour G, Chotel F, Rudigoz RC, Guibal-Baggio AL, Berard J, Pracros JP, et al. Prenatal diagnosis of congenital genu recurvatum following amniocentesis complicated by leakage. Ultrasound Obstet Gynecol 2003;22:643-5.

8. Rampal V, Mehrafshan M, Ramanoudjame M, Seringe R, Glorion C, Wicart P. Congenital dislocation of the knee at birth - Part 2: Impact of a new classification on treatment strategies, results and prognostic factors. Orthop Traumatol Surg Res 2016;102:635-8.

9. Atik OŞ. What are the expectations of an editor from a scientific article? Jt Dis Relat Surg 2020;31:597-8.

10. Oetgen ME, Walick KS, Tulchin K, Karol LA, Johnston CE. Functional results after surgical treatment for congenital knee dislocation. J Pediatr Orthop 2010;30:216-23.

11. Yücel İ , Özturan K, Karaca E, Değirmenci E . Konjenital diz subluksasyonu ve çıkığı: Olgu sunumu ve literatür taramas1. Duzce Med Fac 2005;7:27-31.

12. Hirade T, Katsube K, Kato F. Bilateral congenital dislocation of the knee. J Pediatr 2021;229:299-300.

13. Abdelaziz $\mathrm{TH}$, Samir S. Congenital dislocation of the knee: A protocol for management based on degree of knee flexion. J Child Orthop 2011;5:143-9.

14. Leveuf J, Pais C. Les dislocations congénitales du genou. Rev Chir Orthop 1946;32:313-50.

15. Barber MA, Equiluz I, Plasencia W, Cortes E, Garcia JA. Prenatal features of genu recurvatum and genu flexum. Int J Gynaecol Obstet 2009;105:267-8.

16. Ooishi T, Sugioka Y, Matsumoto S, Fujii T. Congenital dislocation of the knee. Its pathologic features and treatment. Clin Orthop Relat Res 1993;287:187-92.

17. Shah NR, Limpaphayom N, Dobbs MB. A minimally invasive treatment protocol for the congenital dislocation of the knee. J Pediatr Orthop 2009;29:720-5.

18. Ko JY, Shih $\mathrm{CH}$, Wenger DR. Congenital dislocation of the knee. J Pediatr Orthop 1999;19:252-9. 